\title{
Antihypertensive effect of insulin via nitric oxide production in the Zucker diabetic fatty rat, an animal model for non-insulin-dependent diabetes mellitus
}

\author{
Mikiko Kawaguchi, Kunio Koshimura, Yoshio Murakami, Michihiro Tsumori, Tatsuo Gonda ${ }^{1}$ and Yuzuru Kato \\ First Division, Department of Medicine and ${ }^{1}$ Institute of Experimental Animals, Shimane Medical University, Izumo, Japan \\ (Correspondence should be addressed to M Kawaguchi, First Division, Department of Medicine, Shimane Medical University, 89-1 Enya-cho, \\ Izumo 693-850, Japan)
}

\begin{abstract}
It has been reported that insulin treatment improves hypertension in patients with diabetes mellitus. The mechanisms of the antihypertensive effect of insulin, however, remain to be fully elucidated. In the present study, we investigated a possible involvement of nitric oxide (NO) in insulin-induced reduction of blood pressure using the Zucker diabetic fatty (ZDF) rat, an animal model of non-insulin-dependent diabetes mellitus. The animals were divided into three groups and treated for 4 weeks with daily subcutaneous injections of insulin $(25 \mathrm{U} / \mathrm{kg}$ body weight) with or without oral administration of Lnitro-arginine methyl ester (L-NAME, $50 \mathrm{mg} / \mathrm{kg} /$ day body weight as drinking water), an inhibitor of NO synthase (NOS). Saline solution was injected subcutaneously in the control groups. During the experimental period, body weight gain was greater in the insulin-treated groups than in the control groups whereas water intake was considerably decreased in the insulin-treated groups. Insulin treatment resulted in a decrease in plasma glucose and blood pressure, and an increase in both NO metabolites (NOx) in the plasma and NOS activity in the aorta tissue. L-NAME treatment blunted not only the antihypertensive effect of insulin but also the changes in NOx and NOS activity. These findings suggest that insulin reduces blood pressure in the ZDF rat by stimulating NOS activation and NO production.
\end{abstract}

European Journal of Endocrinology 140 341-349

\section{Introduction}

Hypertension is one of the complications in diabetes mellitus (DM) and is considered to be a risk factor for such serious vascular episodes as myocardial infarction and cerebral infarction in diabetic patients $(1,2)$. Insulin has vasodilative and hypotensive effects (3-9). It has been reported that hypertension was improved by insulin treatment in patients with DM (10-12). The antihypertensive effect of insulin was explained either by the secondary action of improved glucose metabolism after insulin treatment or by the direct action on peripheral arterial vessels $(4,10-16)$. Peripheral arterial resistance is a critical factor for the regulation of diastolic blood pressure, which is increased by atherosclerosis or vasoconstriction (17-20).

Recently, nitric oxide (NO) has been identified as an endothelial derived relaxing factor which acts as a modulator of vascular resistance under physiological conditions $(21,22)$. Several lines of evidence suggest that insulin stimulates NO generation in endothelial cells (23-25). Clinically, NO metabolites in plasma and urine increased in diabetic patients treated with insulin $(26-29)$. These results raise the possibility that the antihypertensive effect of insulin is closely related to endothelial NO generation. To clarify this possibility, we examined the antihypertensive effect of insulin in Zucker diabetic fatty (ZDF) rats, in which obesity, hyperglycemia and hyperinsulinemia are genetically expressed at a young age (30). Hypertension occurs after the diabetic state develops in the ZDF rat. Thus, hypertension is considered to be a major vascular complication of DM in the ZDF rat, a model of non-insulin-dependent diabetes mellitus (NIDDM).

In the present study, to investigate the mechanism of antihypertensive effects of insulin, we studied the effects of insulin on plasma glucose, blood pressure and NO generation in ZDF rats. We report our findings suggesting that insulin improves hypertension in DM by stimulating NO synthase activation and NO production.

\section{Materials and methods}

\section{Drugs}

Recombinant human insulin (Novolin N) was purchased from Novo Nordisk (Bagsvaerd, Denmark). 
Guinea pig antiserum to porcine insulin was generated in our laboratory. L-Nitro-arginine methyl ester (L-NAME) was purchased from Aldrich Chemical (Mikwaukee, WI, USA). $\mathrm{L}-\left[{ }^{3} \mathrm{H}\right]$ Arginine $(2.33 \mathrm{GBq} / \mathrm{mmol})$ and L- $\left[{ }^{14} \mathrm{C}\right]$ citrulline $(2.2 \mathrm{GBq} / \mathrm{mmol})$ were purchased from Amersham Life Science (Amersham, Bucks, UK) and New England Nuclear (Boston, MA, USA) respectively. Tetrahydrobiopterin was a generous gift from Suntory Biomedical Research Center, Osaka, Japan. All other chemicals were of the purest grade available from regular commercial sources.

\section{Animals}

Male ZDF rats were obtained at the age of 7 weeks from Genetic Models Inc. (Indianapolis, IN, USA), housed in pairs, and kept in an artificial lighting regime (lights on at $0800 \mathrm{~h}$, off at $2000 \mathrm{~h}$ ). Food and tap water were freely given until the age of 12 weeks when the animals were divided into three groups. In the first and second groups, insulin therapy was started at the age of 12 weeks when plasma glucose levels were over $200 \mathrm{mg} / \mathrm{ml}$. Insulin was injected subcutaneously in a dose of $25 \mathrm{U} /$ $\mathrm{kg} /$ day between $1700 \mathrm{~h}$ and $1800 \mathrm{~h}$ at 24 -h intervals during the next 4 weeks as previously described (31). The second group was also treated with L-NAME, which was administered to drinking water in a dose of $50 \mathrm{mg} / \mathrm{kg} /$ day after the age of 12 weeks. In the third group (control group), saline solution was injected subcutaneously in a dose of $1.25 \mathrm{ml} / \mathrm{kg} /$ day.

After 9 weeks of age, $0.5 \mathrm{ml}$ blood was collected from the tail vein without anesthesia between 0900 and $1100 \mathrm{~h}$ every week as previously described (32). Plasma was obtained by centrifugation at 3000 r.p.m. for $10 \mathrm{~min}$ at $4^{\circ} \mathrm{C}$. Plasma glucose and insulin levels were measured by the glucose oxidase method using Fuji Dry Kem (Fuji Film, Minami Ashigara, Japan), and a specific radioimmunoassay with a rat insulin standard (a generous gift from Eli Lilly and Company, Indianapolis, IN, USA) and guinea pig antiserum to porcine insulin (33). Plasma levels of NO metabolites and osmolarity were measured as previously described $(34,35)$. During the experimental period, food and water intake as well as body weight were monitored at $1800 \mathrm{~h}$ each day. Systolic blood pressure was monitored by the tail-cuff method. After 4 weeks of treatment, all the animals were decapitated and the whole aorta, defined by the aortic arch through the bifurcation of the iliac artery, was removed, immediately frozen in liquid nitrogen and stored at $-80^{\circ} \mathrm{C}$ until the NO synthase (NOS) activity was assayed.

Animal experiments were performed in accordance with the procedures outlined in the Guidelines for Animal Experimentation of Shimane Medical University, which complied with the Guidelines for Animal Experimentation of the Japanese Association for Laboratory Animal Science.

\section{Nitrite $\left(\mathrm{NO}_{2}{ }^{-}\right)$and nitrate $\left(\mathrm{NO}_{3}{ }^{-}\right)$assay}

For the measurement of NO metabolites in rat plasma, $250 \mu \mathrm{l}$ plasma were diluted with the same volume of the mobile phase of the $\mathrm{NOx}\left(\mathrm{NO}_{2}{ }^{-}+\mathrm{NO}_{3}{ }^{-}\right)$analysis system $(10 \%$ methanol containing $0.15 \mathrm{~mol} / \mathrm{l} \mathrm{NaCl}-$ $\mathrm{NH}_{4} \mathrm{Cl}$ and $0.5 \mathrm{~g} / \mathrm{l}$ EDTA4Na) and deproteinized by ultrafiltration with microcon 30 (Amicon, Beverly, MA, USA) at 15000 r.p.m. at $4{ }^{\circ} \mathrm{C}$ for $60 \mathrm{~min}$ and the resulting filtrate was stored at $-20^{\circ} \mathrm{C}$ until assayed.

Nitrite and nitrate concentrations were measured by the NOx analyzing HPLC system (ENO-10, EICOM, Kyoto, Japan). The analysis system consists of a pump for the mobile phase $(10 \%$ methanol containing $0.15 \mathrm{~mol} / \mathrm{l} \mathrm{NaCl}-\mathrm{NH}_{4} \mathrm{Cl}$ and $0.5 \mathrm{~g} / \mathrm{l}$ EDTA4Na, at a
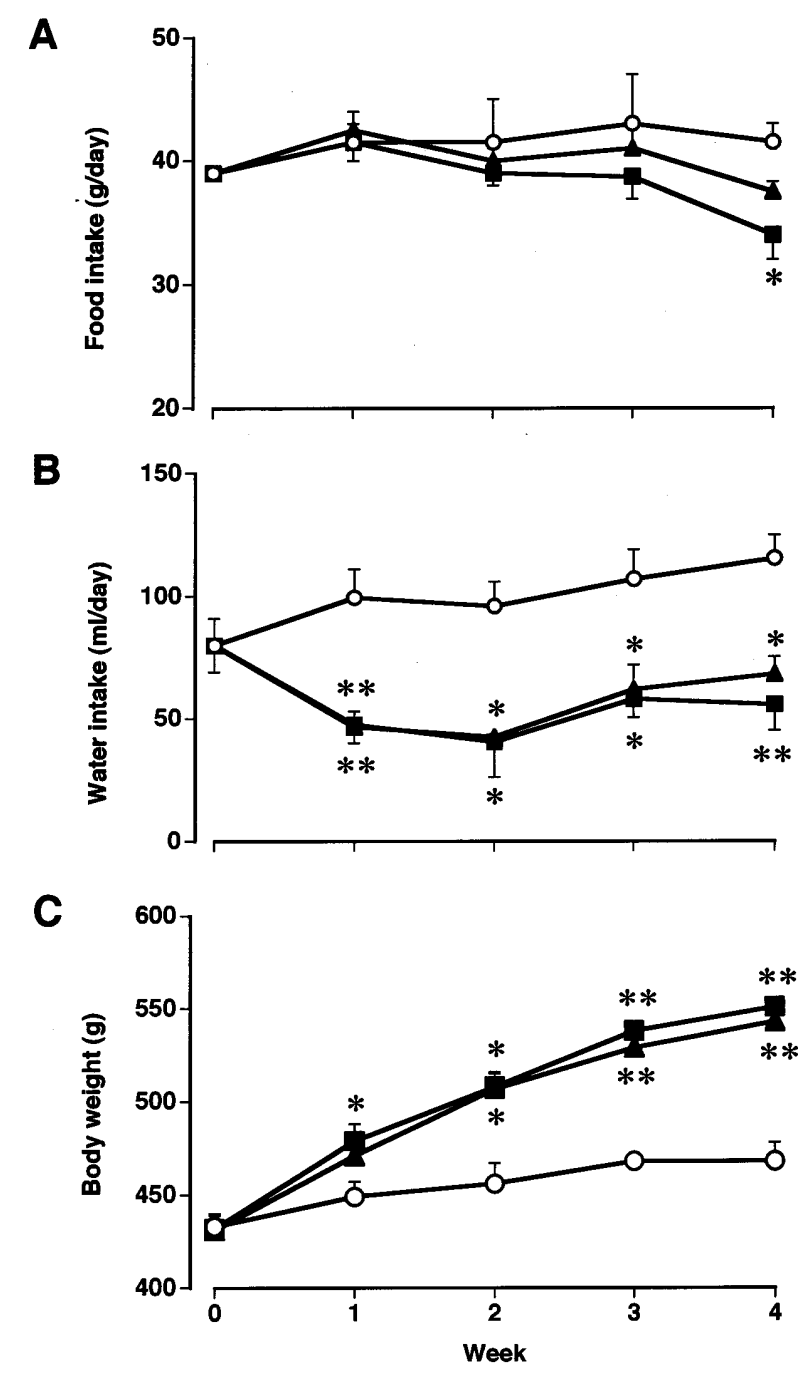

Figure 1 Effects of insulin and L-NAME on food, water intake and body weight in ZDF rats. Food (A), water intake (B) and body weight (C) were monitored at $1800 \mathrm{~h}$ every day. Each value shows the mean \pm S.E.M. of 5 animals examined. (O), Control group; ( $\mathbf{\Lambda})$, insulin-treated group; $(\boldsymbol{\square})$, insulin and L-NAME-treated group. ${ }^{\star} P<0.05,{ }^{\star \star} P<0.01$ vs the control group. 
flow rate of $0.33 \mathrm{ml} / \mathrm{min}$ ), a pump for the Griess reagents $(1.25 \% \mathrm{HCl}$ containing $5 \mathrm{~g} / \mathrm{l}$ sulfanilamide and $0.25 \mathrm{~g} / \mathrm{l} \mathrm{N}$-(1-naphthyl)-ethylenediamine, at a flow rate of $0.1 \mathrm{ml} / \mathrm{min})$, a reverse phase separating column (NO-PAK, $4.6 \mathrm{~mm} \times 50 \mathrm{~mm}$, EICOM), a Cd reducing column (NO-RED, EICOM) and a flow-through spectrophotometer (NOD-10, EICOM). Samples were kept cool and applied to the analysis system by an automated sample injector (AS-8020, Tosoh, Tokyo, Japan). After nitrite and nitrate were separated by a separating column, nitrate was reduced to nitrite by a $\mathrm{Cd}$ reducing column. Then, nitrite was mixed with Griess reagents and a reaction product was measured by a flow-through spectrophotometer at $540 \mathrm{~nm}$. Prior to each experiment, all the tubes and tips for the pipette were washed with purified water prepared by Milli-Q Labo (Millipore, Bedford, MA, USA) to reduce contamination of nitrite and nitrate. $\mathrm{NaNO}_{2}$ and $\mathrm{NaNO}_{3}$ were used as authentic standards.

\section{NOS activity assay}

Rat aortic tissue was homogenized with 10 volumes $50 \mathrm{mmol} / \mathrm{l}$ Tris-HCl (pH 7.4) containing $1 \mathrm{mmol} / \mathrm{l}$ dithiothreitol, $1 \mathrm{mmol} / \mathrm{l}$ EDTA, $10 \mu \mathrm{g} / \mathrm{ml}$ leupeptin, $10 \mu \mathrm{g} / \mathrm{ml}$ aprotinin and $1 \mathrm{mmol} / \mathrm{l}$ phenylmethylsulfonyl fluoride and sonicated twice for $10 \mathrm{~s}$ each. Then the homogenate was centrifuged at $100000 \mathrm{~g}$ for $30 \mathrm{~min}$ at $4^{\circ} \mathrm{C}$. The resulting supernatant was stored at $-80^{\circ} \mathrm{C}$ until assayed.

NOS activity was measured by production of L$\left[{ }^{3} \mathrm{H}\right]$ citrulline from $\mathrm{L}-\left[{ }^{3} \mathrm{H}\right]$ arginine. An aliquot $(50 \mu \mathrm{l})$ of the supernatant was incubated at $37^{\circ} \mathrm{C}$ for $20 \mathrm{~min}$ in the presence of $50 \mathrm{mmol} / \mathrm{l}$ Tris- $\mathrm{HCl}(\mathrm{pH} 7.5), 1 \mathrm{mmol} / \mathrm{l}$ NADPH, $10 \mu \mathrm{mol} / \mathrm{l}$ flavin adenine dinucleotide, $10 \mu \mathrm{mol} / \mathrm{l}$ tetrahydrobiopterin, $40 \mu \mathrm{mol} / \mathrm{l}$ L-arginine, $3.7 \mathrm{MBq} \mathrm{L}-\left[{ }^{3} \mathrm{H}\right]$ arginine and $4 \mathrm{mmol} / \mathrm{l} \mathrm{CaCl}_{2}$ in a total volume of $100 \mu \mathrm{l}$. The reaction was halted by the addition of $1.25 \mathrm{ml}$ ice-cold $20 \mathrm{mmol} / \mathrm{l}$ HEPES ( $\mathrm{pH} 5.5$ ), and the total volume was applied on a Dowex-50 $\mathrm{W} \times 8$
Figure 2 Effects of insulin and L-NAME on plasma insulin and plasma glucose levels in ZDF rats. Blood samples were obtained from the tail vein without anesthesia in the morning each week and plasma was immediately collected for analysis of insulin and glucose levels. Each value shows the mean \pm S.E.M. of 5 animals examined. (O), Control group; ( $\mathbf{\Delta})$, insulin-treated group; (ם), insulin and LNAME-treated group. (A) Effects of insulin and L-NAME on plasma insulin levels in ZDF rats. ${ }^{*} P<0.01$ vs the control group. (B) Effects of insulin and L-NAME on plasma glucose levels in ZDF rats. ${ }^{\star} P<0.05,{ }^{* *} P<0.01$ vs the control group.
A

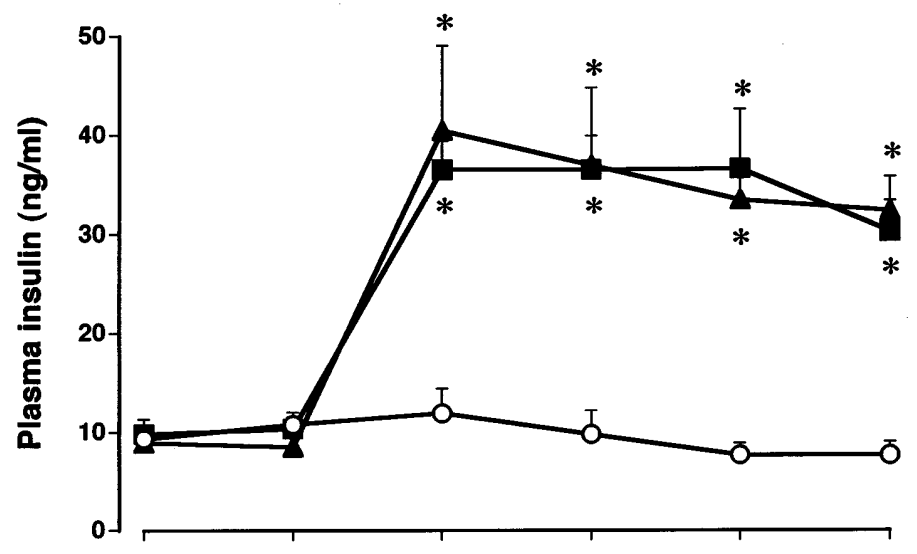

B

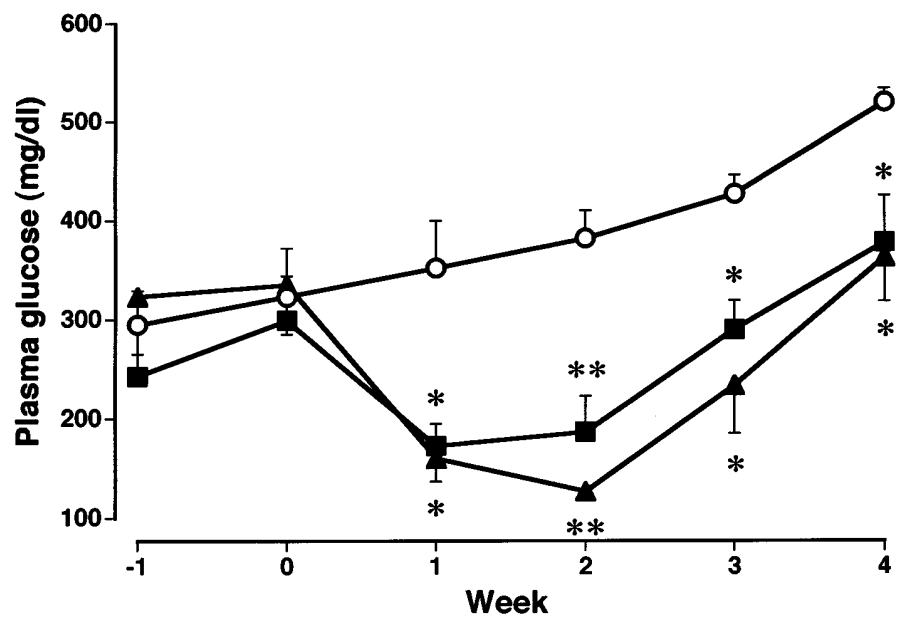


(200-400 mesh, $\mathrm{Na}^{+}$form) column pre-equilibrated with $20 \mathrm{mmol} / \mathrm{l}$ HEPES ( $\mathrm{pH}$ 5.5). L- $\left[{ }^{3} \mathrm{H}\right]$ Arginine was retained on the column, whereas $\mathrm{L}-\left[{ }^{3} \mathrm{H}\right]$ citrulline was recovered in the effluent. Therefore, we collected the follow-through and $2 \mathrm{ml}$ of the distilled water wash, and the radioactivity was measured by a liquid scintillation counter. The recovery of citrulline was determined by applying L- $\left[{ }^{14} \mathrm{C}\right]$ citrulline solution (80-90\%). The concentration of $\mathrm{L}-\left[{ }^{3} \mathrm{H}\right]$ citrulline produced was corrected for recovery.

\section{NADPH diaphorase staining}

After treatment for 4 weeks, the rats were anesthetized with intraperitoneal administration of sodium pentobarbital $(50 \mathrm{mg} / \mathrm{kg})$ and perfused with $300 \mathrm{ml} 0.9 \%$ saline followed by $600 \mathrm{ml} 4 \%$ paraformaldehyde in $0.1 \mathrm{~mol} / \mathrm{l}$ phosphate buffer $(\mathrm{pH}$ 7.4) via the left ventricle. The whole aorta, defined by the aortic arch through the bifurcation of the iliac artery, was removed and immersed in the same fixative at $4{ }^{\circ} \mathrm{C}$ overnight. After washing with $0.1 \mathrm{~mol} / \mathrm{l}$ phosphate buffer three times, one half of the aorta was cryoprotected at $4{ }^{\circ} \mathrm{C}$ overnight by gradually increasing the sucrose concentrations by $10 \%, 20 \%$ and $30 \%$ at 24 -h intervals. Then the aortic tissue was embedded in OCT compound and frozen in liquid nitrogen. Frozen sections $(20 \mu \mathrm{m})$ were cut using a cryostat (coldtome, model CM-41, Sakura, Tokyo, Japan) and placed on poly-L-lysine-coated glass slides. Aortic sections were incubated at $4{ }^{\circ} \mathrm{C}$ in the dark overnight in $0.1 \mathrm{~mol} / \mathrm{l}$ phosphate buffer containing $1.2 \mathrm{mmol} / \mathrm{l} \beta$-NADPH as a reduced form, $0.3 \mathrm{mmol} / \mathrm{l}$ nitro blue tetrazolium and $0.2 \%$ Triton $\mathrm{X}-100$. The reaction was terminated by washing the sections with ice-cold $0.1 \mathrm{~mol} / \mathrm{l}$ phosphate buffer $(\mathrm{pH} 7.4)$. Sections were then cover-slipped with glycerol. Several sections were then dehydrated by ethanol and embedded in paraffin. Slices $(5 \mu \mathrm{m})$ were prepared for hematoxylineosin (HE) staining by the use of a rotary microtome (RM 2135, Leica, Heidelberger, Germany) as previously described $(36,37)$.

\section{Statistical analysis}

All results are expressed as means \pm s.E.M. The statistical differences were evaluated with ANOVA and Fisher's test. A probability level of $P<0.05$ was considered significant.

\section{Results}

Food intake was constantly preserved during the experimental period in the control group. In the
A
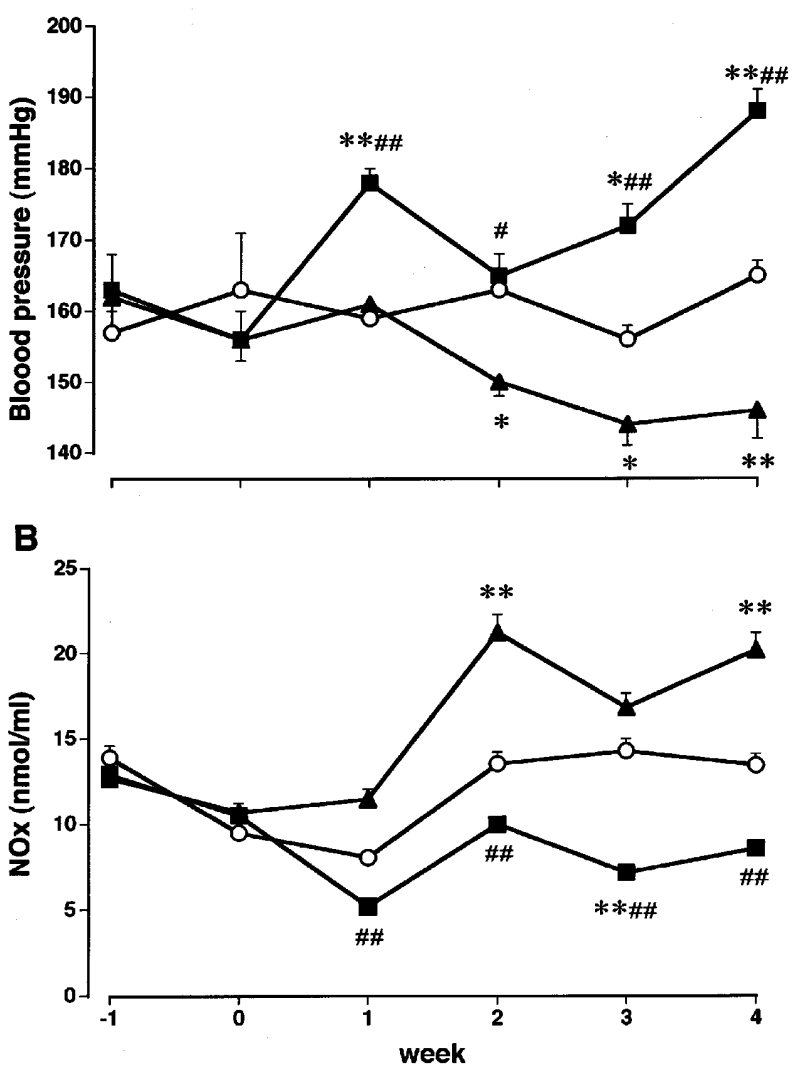

Figure 3 Effects of insulin and L-NAME on systolic blood pressure and plasma NOx concentrations in ZDF rats. Each value shows the mean \pm S.E.M. of 5 animals examined. (O),

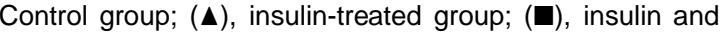
L-NAME-treated group. (A) Effect of insulin on systolic blood pressure in ZDF rats. Systolic blood pressure was measured by the tail cuff method in the morning each week. (B) Effect of insulin on plasma NOx levels in ZDF rats. Blood samples were obtained from the tail vein without anesthesia in the morning each week and plasma was ultrafiltrated for analysis of $\mathrm{NO}_{2}{ }^{-}$and $\mathrm{NO}_{3}{ }^{-}$. Plasma $\mathrm{NOx}$ concentrations were measured by the NOx analysis system as described in the text. ${ }^{*} P<0.05,{ }^{* \star} P<0.01$ vs the control group. $\# P<0.05$, $\# \# P<0.01$ vs the insulin-treated group. 
insulin-treated group and the group treated with insulin and L-NAME, food intake was similar until 3 weeks after the start of the treatment, but it was lower in the latter group at 4 weeks after the start of treatment. Water intake markedly decreased and remained low until the end of the experiment in both the insulin-treated group and the insulin and L-NAME-treated group as compared with the control group (Fig. 1A, B).The body weight of the insulin-treated rats was much greater one week after the administration of insulin and remained greater until the end of the experiment. The body weight of the insulin and L-NAME-treated rats was also greater two weeks after the start of treatment and remained greater in a similar manner to the insulintreated rats. There was no statistical difference in the body weight between the insulin-treated rats and the insulin and L-NAME-treated rats (Fig. 1C).

Plasma insulin levels markedly increased after the injection of insulin both in insulin-treated rats and in insulin and L-NAME-treated rats. The plasma insulin level in the control group remained fairly constant from the 12th week until the end of the experiment (Fig. 2A). Plasma glucose levels decreased after the administration of insulin both in the insulin-treated rats and in the insulin and L-NAME-treated rats. The effect of insulin on plasma glucose was independent of L-NAME. In both groups, the plasma glucose level remained low until two weeks after the administration of insulin, then the plasma glucose level gradually increased even in the presence of insulin. However, the plasma glucose level was significantly lower in both the insulin-treated rats and the insulin and L-NAME-treated rats compared with the control rats during treatment with insulin (Fig. 2B).

Compared with the control group, systolic blood pressure decreased in the insulin-treated rats two weeks after the start of insulin administration and remained low until the end of the experiment. Systolic blood pressure was greater in the insulin and L-NAME-treated rats than in the control group one week after the start of insulin administration, and remained higher until the end of the experiment except at two weeks after insulin administration (Fig. 3A).

Plasma NOx levels increased during the treatment with insulin whereas simultaneous administration of L-NAME blunted the insulin-induced increase in plasma NOx and reduced plasma NOx levels compared with the control group (Fig. 3B).

NOS activity in the aortic tissue remarkably increased in the group treated with insulin whereas it was not considerably changed in the insulin and L-NAMEtreated group and in the control group (Fig. 4).

HE staining revealed that the smooth muscle layer of the aorta in the insulin-treated group was apparently thin due to aortic dilatation and that the aortic smooth muscle layer of the insulin and L-NAME-treated group was apparently thick due to aortic constriction compared with the control group (Fig. 5A, B and C). NADPH diaphorase staining showed that the endothelium and the smooth muscle in the aorta were more densely stained in the insulin-treated group than in the control group. Among the three groups these areas were most densely stained in the insulin and L-NAME-treated group (Fig. 5D, E and F).

\section{Discussion}

In the present study we have clearly demonstrated that insulin treatment improved hypertension associated with DM possibly via stimulated NOS activation and NO production.

In the ZDF rats, increased plasma glucose levels were evident at the age of 12 weeks, when insulin treatment was started. Although the dose of insulin administered increased according to the body weight gain in these animals, plasma glucose levels gradually increased. This may be due to an increase in the resistance to insulin since plasma insulin levels were threefold higher in the ZDF rat than those in the Lean rat, a non-diabetic phenotype for the ZDF rat, at the age of 9 weeks, and remained high at the age of 16 weeks (data not shown). It is likely that the insulin-induced increase in body weight was caused by improved metabolism which induces a decrease in water intake and an accumulation of fat in the subcutaneous tissue.

Increases in body weight, plasma glucose levels and insulin resistance in $\mathrm{ZDF}$ rats are compatible with clinical findings in obese patients with NIDDM. In the

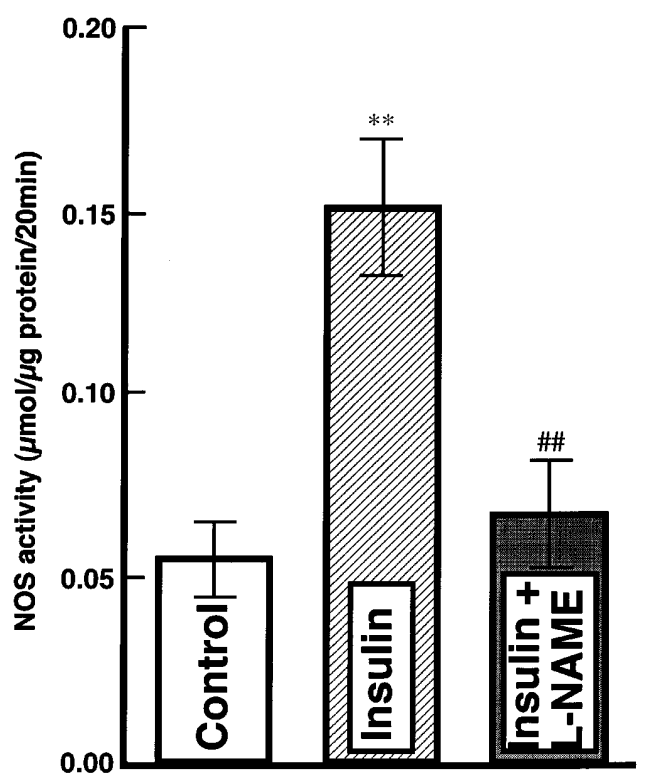

Figure 4 Effects of insulin and L-NAME on NOS activity in the aorta of ZDF rats. At the end of the experimental period, the aorta was removed and homogenized for analysis of NOS activity. NOS activity was measured by production of $L-\left[{ }^{3} \mathrm{H}\right]$ citrulline from $\mathrm{L}-\left[{ }^{3} \mathrm{H}\right]$ arginine as described in the text. Each value shows the mean \pm S.E.M. of 4 animals examined. ${ }^{* *} P<0.01$ vs the control group. \#\#P<0.01 vs the insulin-treated group. 

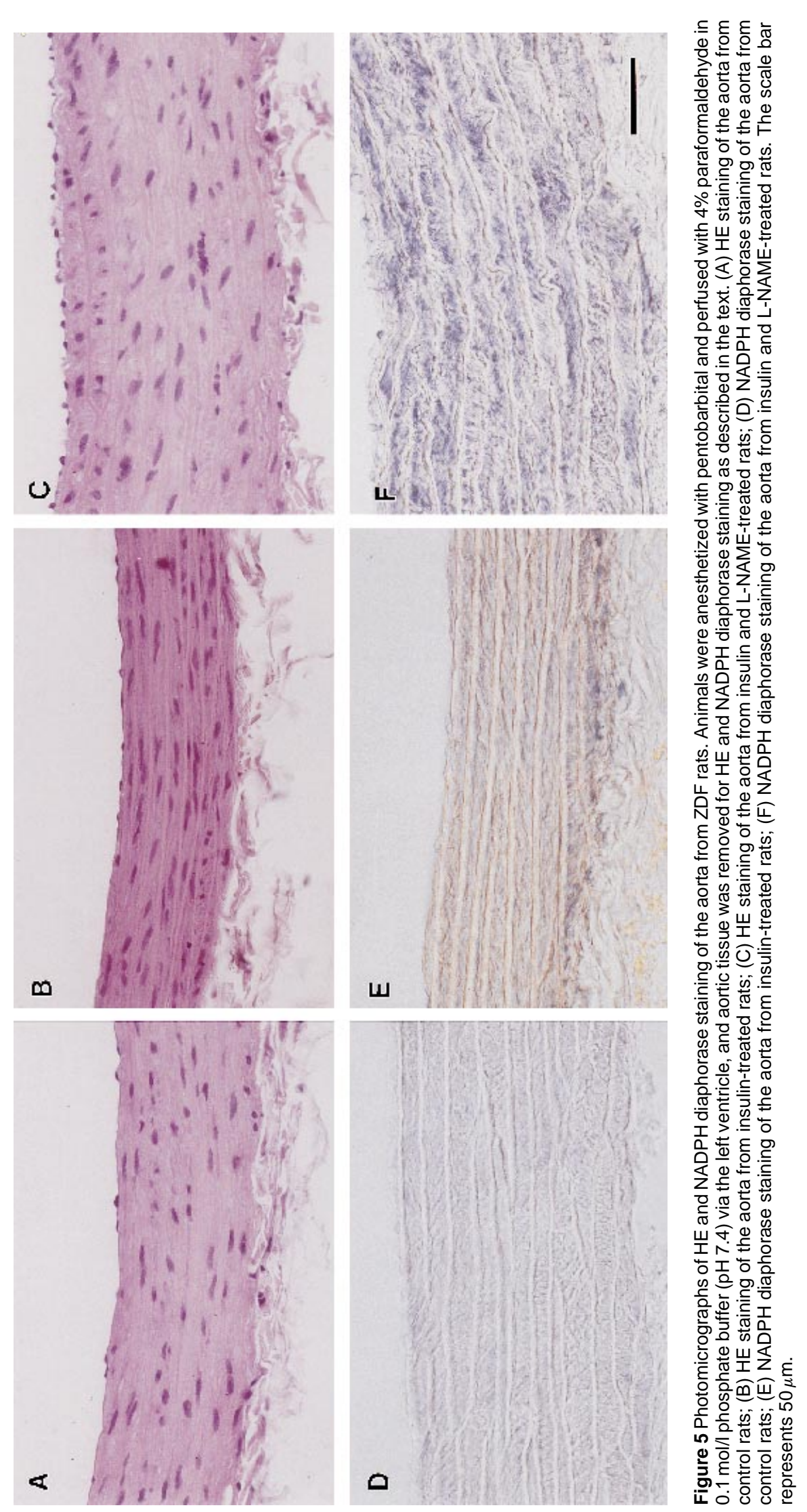
ZDF rats, hypertension invariably occurs at a certain age after the onset of DM. This may be explained by proliferation of vascular smooth muscle induced by sympathetic stimulation $(38)$ or insulin $(6,11,39)$, or by reduction of insulin-induced vasodilatation due to increased insulin resistance $(6,11,40-42)$. Therefore, it is considered that the ZDF rat may be a model of NIDDM associated with major vascular complications.

Systolic blood pressure was higher in the ZDF rat than in the Lean rat at the age of 12 weeks, but improved after insulin treatment in the ZDF rat. The antihypertensive effect of insulin continued until the end of the experiments. In contrast, administration of L-NAME, an inhibitor of NOS, together with insulin increased blood pressure above the level of non-treated ZDF rats. Although insulin is reported to stimulate reabsorption of sodium at the renal tubules (43), there was no significant difference in plasma osmolarity and sodium concentrations among the three groups examined (control, insulin-treated and insulin and L-NAMEtreated rats) (data not shown). $\mathrm{NO}_{3}{ }^{-}$was the predominant NO metabolite detected in rat plasma and the plasma level of $\mathrm{NO}_{2}{ }^{-}$was almost negligible in all the groups (data not shown). Plasma $\mathrm{NOx}\left(\mathrm{NO}_{2}{ }^{-}+\mathrm{NO}_{3}{ }^{-}\right)$ concentrations increased in the insulin-treated rats but not in either the non-treated control rats or the rats treated with insulin and L-NAME. In the rats treated with insulin and L-NAME, plasma NOx concentrations decreased. These results suggest that the antihypertensive effect of insulin is possibly mediated by NO. Systolic blood pressure increased in the insulin and L-NAMEtreated rats above that of the control rats, and plasma NOx concentrations decreased in these animals below those of the control rats. These findings suggest that NO is acting tonically on the blood vessels in the ZDF rats. L-NAME is considered to have no effect on insulin secretion $(44,45)$, and the dose of insulin used in the present study is considerably higher than physiological plasma insulin concentrations (46). Therefore, an involvement of endogenous insulin may be negligible in the insulintreated group. The physiological role of endogenous insulin on blood pressure remains to be clarified.

NO is considered to be a modulator of vascular tension, which is predominantly derived from vascular endothelial cells (47-49). To investigate the effect of exogenous insulin on NO production in the endothelial cells, we carried out in vitro NOS activity assay and NADPH diaphorase staining in the aorta tissues. NOS activity in the aorta was increased after insulin treatment, suggesting an increase in NOS molecule in the aorta by insulin administration. NOS activity of the aorta was not changed in the rats treated with insulin and L-NAME although plasma NOx concentration, as an index of in vivo NOS activity, was decreased compared with the control group.

HE staining showed that the insulin-treated aorta was dilated whereas the aorta treated with insulin and L-NAME was constricted. These results were compatible with the blood pressure changes observed in the insulintreated rats and insulin and L-NAME-treated rats. NADPH diaphorase staining revealed that the aorta of the insulin-treated rats was densely stained and that the aorta of the rats treated with insulin and L-NAME was stained even more densely than the insulin-treated rats. These results suggest that NOS molecule was induced in both the insulin-treated group and the insulin and L-NAME-treated group. Plasma NOx concentrations were higher in the insulin-treated rats than in the control rats. The data of the insulin-treated rats taken together suggest that insulin stimulates the synthesis of NOS molecule, resulting in an increase in NO production.

In the insulin and L-NAME-treated rats, in vitro NOS activity in the aorta and NADPH diaphorase staining are not consistent. The data of the rats treated with insulin and L-NAME apparently showed that in vitro NOS activity in the aorta was not increased but that NOS molecule detected with NADPH diaphorase staining was increased. Since plasma NOx concentrations were lower in the rats treated with insulin and L-NAME than in the control rats, in vivo NOS activity was decreased in the rats treated with insulin and L-NAME. It is assumed that reduction of NO production positively stimulates the synthesis of NOS molecule, resulting in dense staining of NADPH diaphorase in the endothelial cells of the insulin and L-NAME-treated rats. When in vitro NOS activity in the aorta of the insulin and L-NAME-treated rats was measured, L-NAME may still have bound to the NOS molecule, resulting in a discrepancy between NADPH diaphorase staining and in vitro NOS activity in the aorta of insulin and L-NAME-treated rats.

Although we did not examine the effect of insulin on small arteries, resistance of which is physiologically involved in regulating blood pressure, our findings in the aorta suggest that insulin treatment decreases blood pressure in the ZDF rats by enhancement of NO production via induction of NOS molecule synthesis in endothelial cells.

\section{Acknowledgements}

This work was supported in part by grants from the Ministry of Education and Culture, Japan, the Ministry of Health and Welfare, Japan, and the Shimane Institute for Intractable Diseases. We thank Mrs A Kanayama for her technical assistance and Mrs A Kawakami for her secretarial help.

\section{References}

1 Mehler PS, Jeffers BW, Estacio R \& Schrier RW. Association of hypertension and complications in non-insulin-dependent diabetes mellitus. American Journal of Hypertension 199710 152-161.

2 Meigs JB, Singer DE, Sullivan LM, Dukes KA, D'Agostino RB, Nathan DM et al. Metabolic control and prevalent cardiovascular disease in non-insulin-dependent diabetes mellitus (NIDDM): the 
NIDDM patient outcome research team. American Journal of Medicine 1997102 38-47.

3 Hall JE, Coleman TG, Mizelle HL \& Smith MJ Jr. Chronic hyperinsulinemia and blood pressure regulation. American Journal of Physiology 1990258 F722-F731.

4 Hall JE, Brands MW, Kivlighn SD, Mizelle HL, Hildebrandt DA \& Gaillard CA. Chronic hyperinsulinemia and blood pressure: interaction with catecholamine? Hypertension 199015 519527.

5 Brands MW, Mizelle HL, Gaillard CA, Hildebrandt DA \& Hall JE. The hemodynamic response to chronic hyperinsulinemia in conscious dogs. American Journal of Hypertension 19914 164-168.

6 Baron AD \& Brechtel G. Insulin differentially regulates systemic and skeletal muscle vascular resistance. American Journal of Physiology 1993265 E61-E67.

7 Baron AD, Brechtel-Hook G, Johnson A \& Hardin D. Skeletal muscle blood flow: a possible link between insulin resistance and blood pressure. Hypertension 199321 129-135.

8 Gans RO, Bilo HJ \& Donker AJ. The renal response to exogenous insulin in non-insulin-dependent diabetes mellitus in relation to blood pressure and cardiovascular hormonal status. Nephrology, Dialysis, Trasnsplantation 199611 794-802.

9 Giugliano D, Marfella R, Verrazzo G, Acampora R, Coppola L, Cozzolino D et al. The vascular effects of L-arginine in humans the role of endogenous insulin. Journal of Clinical Investigation $199799433-438$

10 Anderson EA, Hoffman RP, Balon TW, Sinkey CA \& Mark AL. Hyperinsulinemia produces both sympathetic neural activation and vasodilatation in normal humans. Journal of Clinical Investigation 199187 2246-2252.

11 Anderson EA \& Mark AL. The vasodilator action of insulin: implications for the insulin hypothesis of hypertension. Hypertension 199321 136-141.

12 Baron AD. Hemodynamic actions of insulin. American Journal of Physiology 1994267 E187-E202.

13 Scott AR, Bennet T \& Macdonald IA. Effects of hyperinsulinemia on the cardiovascular responses to graded hypovolemia in normal and diabetic subjects. Clinical Science 198875 85-92.

14 Natali A, Buzzigoli G, Taddei S, Santori D, Cerri M, Pedrinelli R et al. Effects of insulin on hemodynamics and metabolism in human forearm. Diabetes 199039 490-500.

15 Anderson EA, Hoffmann RP, Balon TW, Sinkey CA \& Mark AL. Hyperinsulinemia in humans increases muscle sympathetic nerve activity, but reduces forearm vascular resistance. Clinical Research $199020219-225$

16 Vollenweider P, Tappy L, Randin D, Schneiter P, Jequier E, Nicod P et al. Differential effects of hyperinsulinemia and carbohydrate metabolism on sympathetic nerve activity and muscle blood flow in humans. Journal of Clinical Investigation 199392 147-154.

17 Folkow B. Hypertensive structural changes in systemic precapillary resistance vessels: how important are they for in vivo hemodynamics? Journal of Hypertension 199513 1546-1559.

18 Heagerty AM \& Izzard AS. Small-artery changes in hypertension. Journal of Hypertension 199513 1560-1565.

19 Heistad DD, Baumbach GL, Faraci FM \& Armstrong ML. Sick vessels syndrome: vascular changes in hypertension and atherosclerosis. Journal of Human Hypertension 19959 449-453.

20 Izzard AS \& Heagerty AM. Hypertension and the vasculature: arterioles and the myogenic response. Journal of Hypertension $1995131-4$.

21 Vane JR, Änggård EE \& Botting RM. Mechanisms of disease: regulatory functions of the vascular endothelium. New England Journal of Medicine 1990323 27-36.

22 Dinerman JL, Lowenstein CJ \& Snyder SH. Molecular mechanisms of nitric oxide regulation: potential relevance to cardiovascular diseases. Circulation Research 199373 217-222.

23 Sobrevia L, Nadal A, Yudilevich DL \& Mann GE. Activation of L-arginine transport (system $y+$ ) and nitric oxide synthase by elevated glucose and insulin in human endothelial cells. Journal of Physiology $1996490775-781$.
24 Zeng G \& Quon MJ. Insulin-stimulated production of nitric oxide is inhibited by wortmannin: direct measurement in vascular endothelial cells. Journal of Clinical Investigation 199698 894-898.

25 Tsukahara H, Kikuchi K, Tsumura K, Kimura K, Hata I, Hiraoka M et al. Experimentally induced acute hyperinsulinemia stimulates endogenous nitric oxide production in humans: detection using urinary $\mathrm{NO}_{2}{ }^{-} / \mathrm{NO}_{3}{ }^{-}$excretion. Metabolism $199746406-409$.

26 Scherrer U, Randin D, Vollenweider P, Vollenweider L \& Nicod O. Nitric oxide release accounts for insulin's vascular effects in humans. Journal of Clinical Investigation 199494 2511-2515.

27 Steinberg HO, Brechtel G, Johnson A, Fineberg N \& Baron AD. Insulin-mediated skeletal muscle vasodilatation is nitric oxide dependent: a novel action of insulin to increase nitric oxide release. Journal of Clinical Investigation $1994941172-$ 1179.

28 McKay MK \& Hester RL. Role of nitric oxide, adenosine, and ATPsensitive potassium channels in insulin-induced vasodilatation. Hypertension $199628202-208$.

29 Avogaro A, Piarulli F, Varelio A, Miola M, Calveri M, Pavan P et al. Forearm nitric oxide balance, vascular relaxation, and glucose metabolism in NIDDM patients. Diabetes 199746 10401046.

30 Clark JB, Palmer CJ \& Shaw WN. The diabetic zucker fatty rat. Proceedings of the Society for Experimental Biology and Medicine $198317368-75$.

31 Tanigawa K, Kawaguchi M, Tanaka O \& Kato Y. Skeletal malformations in rat offspring: long-term effect of maternal insulin-induced hypoglycemia during organogenesis. Diabetes $1991401115-1121$

32 Kawaguchi M, Tanigawa K \& Kato Y. A study of the effect of CS-045, a new antidiabetic drug, on hypertension in spontaneously hypertensive rat. Endocrine Journal 199542 557-561.

33 Deabuquois B \& Aurbach GD. Use of polyethylene glycol to separate free and antibody-bound peptide hormones in radioimmunoassays. Journal of Clinical Endocrinology and Metabolism $197133732-738$.

34 Kawaguchi M, Tanigawa K, Tanaka O \& Kato Y. Embryonic growth impaired by maternal hypoglycemia during early organogenesis in normal and diabetic rats. Acta Diabetologica $199431141-146$.

35 Xu G, Tanigawa K, Nakamura S, Kawaguchi M, Kato Y \& Tamura K. $\beta$-Cell function and replication in spontaneously hypertensive rats. Metabolism 199544 1360-1364.

36 Inoue Y, Tanigawa K, Nakamura S, Xu G, Kawaguchi M, Kato Y et al. Lack of effect of CS-045, a new antidiabetic agent, on insulin secretion in the remnant pancreas after $90 \%$ pancreatectomy in rats. Diabetes Research and Clinical Practice 199527 19-26.

37 Tanigawa K, Xu G, Nakamura S, Kawaguchi M, Kato Y \& Tamura $\mathrm{K}$. Impaired compensatory adaptation to B-cell mass reduction in young spontaneously hypertensive rats (SHR). Pancreas 199612 237-242.

38 Reaven GM, Lithell H \& Landsberg L. Hypertension and associated metabolic abnormalities - the role of insulin resistance and the sympathoadrenal system. New England Journal of Medicine 1996 334 374-381.

39 Baron AD. The coupling of glucose metabolism and perfusion in human skeletal muscle: the potential role of endothelium-derived nitric oxide. Diabetes 199645 (Suppl) S105-S109.

40 Laakso M, Edelman SV, Brechtel G \& Baron AD. Decreased effect of insulin to stimulate skeletal muscle blood flow in obese man: a novel mechanism for insulin resistance. Journal of Clinical Investigation $1990851844-1852$.

41 Laakso M, Edelman SU, Brechtel G \& Baron AD. Impaired insulinmediated skeletal muscle blood flow in patients with NIDDM. Diabetes 199241 1076-1083.

42 Steinberg HO, Chaker H, Leaming R, Johnson A, Brechtel G \& Baron AD. Obesity/insulin resistance is associated with endothelial dysfunction - implications for the syndrome of insulin resistance. Journal of Clinical Investigation 199697 2601-2610 
43 Gans RO, v.d. Toorn L, Bilo HJG, Nauta JJP, Heine RJ \& Donker AJM. Renal and cardiovascular effects of exogenous insulin in healthy volunteers. Clinical Science $199180219-225$.

44 Panagiotidis G, Alm P \& Lundquist I. Inhibition of islet nitric oxide synthase increases arginine-induced insulin release. European Journal of Pharmacology 1992229 277-278.

45 Coiro V, Volpi R, Capretti L, Speroni G, Caffarri G \& Chiodera P Involvement of nitric oxide in arginine, but not glucose, induced insulin secretion in normal men. Clinical Endocrinology 199746 115-119.

46 Boden G, Ruiz J, Urbain JL \& Chen X. Evidence for a circadian rhythm of insulin secretion. American Journal of Physiology 1996 271 E246-E252.
47 Busse R, Fleming I \& Hecker M. Signal transduction in endothelium-dependent vasodilatation. European Heart Journal 199314 (Suppl 1) 2-9.

48 Vanhoutte PM \& Mombouli JV. Vascular endothelium: vasoactive mediators. Progress in Cardiovascular Diseases 199639 229238.

49 Vanhoutte PM. Endothelium and control of vascular function: state of art lecture. Hypertension 198913 658-667.

Received 30 December 1998

Accepted 19 January 1999 